\title{
Outcomes of laparoscopic sleeve gastrectomy by means of esophageal manometry and pH-metry, before and after surgery
}

\author{
Eyup Gemici ${ }^{1}$, Osman Kones ${ }^{1}$, Hakan Seyit ${ }^{1}$, Ahmet Surek ${ }^{1}$, Murat Cikot ${ }^{1}$, Mehmet Abdussamet Bozkurt ${ }^{1}$, Halil Alis ${ }^{2}$ \\ ${ }^{1}$ Department of General Surgery, Faculty of Medicine, University of Health Sciences, Bakirkoy Dr. Sadi Konuk Health Practice \& Research \\ Center, Istanbul, Turkey \\ ${ }^{2}$ Department of General Surgery, Faculty of Medicine, Istanbul Aydin University, Istanbul, Turkey
}

Videosurgery Miniinv 2020; 15 (1): 129-135

DOI: https://doi.org/10.5114/wiitm.2019.83198

\begin{abstract}
Introduction: Gastroesophageal reflux is a major problem after sleeve gastrectomy. There is still insufficient understanding of how it occurs and whether it is due to the sphincter length, relaxation, or pressure differences.

Aim: This study evaluates the effect on the lower esophageal sphincter of the laparoscopic sleeve gastrectomy (LSG) technique applied in surgery in cases of morbid obesity using ambulatory 24- $h$ pH monitoring (APM) and esophageal manometry (EM).

Material and methods: A retrospective examination was carried out on the APM and EM tests performed preoperatively and postoperatively in cases of LSG. The parameters examined were the body mass index (BMI), amplitude pressure of the esophagus (AP), total length of the lower esophageal segment (LESL), resting pressure of the LES (LESP), residual pressure of the LES (LESR), relaxation time of the LES, intragastric pressure, and the DeMeester score. Results: A total of 62 cases with available data were evaluated. A statistically significant difference was determined between the preoperative values and the 3-month postoperative values of BMI, LESP, and relaxation time of the LES. A statistically significant increase was determined in the DeMeester score, and the increase in the total number of reflux episodes longer than 5 min was found to be the most responsible for this increase. No significant difference was determined in the other parameters.

Conclusions: The LSG was found to cause a reduction in LESP, and an increase in acid reflux causing an extended relaxation time of the LES. This was confirmed by the increase seen in the DeMeester score.
\end{abstract}

Key words: sleeve gastrectomy, gastroesophageal reflux disease, esophageal manometry, DeMeester score, 24-hour pH monitoring.

\section{Introduction}

In the last 30 years, obesity has become a chronic disease that is threatening humanity in the form of a global pandemic [1]. Solutions are being intensively sought to address the changes and restrictions in daily life, the high morbidity, the loss of work force, and costs associated with obesity. There has been a great increase in the frequency of obesity surgery performed in the last 10 years, which is now a widely used procedure throughout the world [2].

Bariatric surgery is performed to reduce calorie intake or prevent the absorption of calories consumed. The techniques applied can be divided into restrictive methods, malabsorptive methods, and combinations of both [3]. Laparoscopic sleeve gastrectomy (LSG) is a restrictive technique and is the most commonly used procedure in obesity surgery

Address for correspondence

Dr. Eyup Gemici, Department of Surgery, Faculty of Medicine, University of Health Sciences, Bakirkoy Dr. Sadi Konuk Health Practice

\& Research Center, Building A, Floor 4, Tevfik Saglam Cad. Nr: 11, 34147, Bakirkoy, Istanbul, Turkey, phone: +90 5366795813,

e-mail: eyupgemici@yahoo.com 
throughout the world [4]. The technique is popular because it is well defined, it is easier to perform than other types of bariatric surgery, the learning curve is shorter, the morbidity and mortality rates are low, and it leads to effective weight loss [5].

Nevertheless, the effect of LSG on the natural physiological functions of the esophagus and stomach has not been clearly established. Reflux symptoms are seen at higher rates in obese subjects, which increases the complexity of this natural process [6, 7]. Esophagitis, Barrett's esophagus, and symptoms of adenocarcinoma could cause gastro-esophageal reflux disease and are serious causes of mortality [8]. Studies on sleeve gastrectomy surgery have commonly examined the motility of the esophagus and the behavior of the lower esophagus sphincter and remnant stomach.

Ambulatory 24-hour esophageal $\mathrm{pH}$ monitoring (APM) and esophagus manometry (EM) have been successfully used for the evaluation of esophagus and stomach pathophysiology. Studies that have investigated the efficacy of LSG have almost all used these tests. Factors that protect against reflux include peristaltic contractions of the esophagus at a sufficient severity (30-150 mm Hg), lower tonus (10$25 \mathrm{~mm} \mathrm{Hg}$ ) of the esophagus sphincter (which functions as a valve), and robustness in terms of a lack of pathology [9]. An increase in weight increases the intra-abdominal pressure, which is directly associated with increased intragastric pressure. The resting tonus decreases as a result of removing the angle of His from the expanded stomach and shortening the lower esophagus sphincter. However, the primary basic factor is transient lower esophageal sphincter relaxation (TLESR). With the protective mechanisms not functioning, a pathological reflux process begins [10].

Many studies have reported that de novo pathological reflux is seen or that reflux symptoms are worsened following sleeve gastrectomies in which the mean excess weight loss (EWL) is 60\% [11-13]. This seems to be a serious contradiction and suggests a negative effect of sleeve gastrectomy on the gastro-esophageal gradient, in contrast to the weight loss. This study was designed to address this issue. APM and EM measurements were taken preoperatively and at 3 months postoperatively in patients who underwent sleeve gastrectomy.

\footnotetext{
Aim

The aim of the study was to present the effects of sleeve gastrectomy on esophagus contraction,
}

lower esophagus sphincter, acid reflux, and intragastric pressure.

\section{Material and methods}

The same physicians performed the operations using the same technique between 2016 and 2017. Before the operation, a routine anesthesia preparation was administered, and upper gastrointestinal endoscopy, APM, and EM were carried out. At 3 months postoperatively, APM and EM were carried out again, and the results were compared with the preoperative values. Sleeve gastrectomy was applied to all the patients in the study. Patients were excluded if they had an esophageal motor disorder, an advanced stage of hiatus hernia (grades III and IV), or if any complications developed postoperatively.

The APM was carried out preoperatively and at 3 months postoperatively. A pH catheter was applied to all patients (Versaflex, Given Imaging, GA, USA), and no proton-pump inhibitors were used for a period of at least 10 days. The sensor was calibrated in $\mathrm{pH}$ buffer solutions of $\mathrm{pH} 7$ and $\mathrm{pH} 1$ and then positioned $5 \mathrm{~cm}$ above the upper border of the LES. All patients completed a standardized diary and were encouraged to perform normal daily activities. No specific food restrictions or standardized diets were applied. The data were recorded and transferred to a computer for analysis (Polygram Net pH Testing System, Medtronic, USA). The analysis included the total percentage time of $\mathrm{pH}<4.0$, the total number of reflux episodes, the total number of reflux episodes longer than $5 \mathrm{~min}$, and the duration of the longest reflux episode. The DeMeester score was calculated and was considered abnormal if $>14.72$.

The EM was applied preoperatively and at 3 months postoperatively using Solar GI Air-Charged Intelligent Gastrointestinal Conventional Manometry (Medical Measurement Systems, The Netherlands). A 4-channel air-charged circumferential pressure catheter (Latitude Gastrointestinal Manometry Catheter Clinical Innovations, Inc., Murray, Utah) with a $5-\mathrm{cm}$ distance between the sensors was inserted through a nostril and positioned to straddle the gastroesophageal junction.

The LES pressure (LESP) was calculated as the difference between the end-expiratory LESP and the end-expiratory gastric pressure using the station pull-through technique. All the pressure values referred to atmospheric pressure and were stated 
in $\mathrm{mm} \mathrm{Hg}$. After measurements of the intra-gastric pressure were taken with the distal sensor, the catheter was pulled back for placement on the lower esophageal sphincter. Esophageal body contractions were measured using 4 sensors positioned at 0,5 , 10 , and $15 \mathrm{~cm}$ above the LES. Using $5 \mathrm{ml}$ of water, 10 consecutive wet swallows at 30-second intervals were measured. In the analysis of the swallows, the values examined were the total length of the LES, LESP, residual pressure of LES (LESR), relaxation time of the LES, amplitude pressure of the esophagus $(A P)$, and intragastric pressure.

The LSG procedure was applied with the division of the greater curvature vessels using a Ligasure device (Covidien, USA) starting at $1 \mathrm{~cm}$ from the pylorus as far as the angle of His to cut the short gastric and posterior fundic vessels. Upon completion of this maneuver, a $36-\mathrm{Fr}$ bougie was introduced into the stomach by the anesthesiologist and advanced by the surgeon along the lesser curvature into the pyloric channel and duodenal bulb. An EndoGIA device (Covidien, USA) with 4.8-mm staplers (green charge) was introduced through the $15-\mathrm{mm}$ port in the right quadrant to start the division of the antrum $2-3 \mathrm{~cm}$ from the pylorus. This was completed with another green charge to the angular incision.

Using a stapler, a pouch was created starting approximately $2-3 \mathrm{~cm}$ proximal to the pylorus and continuing parallel to the lesser curvature of the stomach as far as the angle of His and terminating approximately $1 \mathrm{~cm}$ to the left of the esophagus with 3-4 charges of a 3.8-mm stapler (EndoGIA; blue charge). To ensure that there was no leakage along the suture line and to assess the gastric capacity, methylene blue was instilled through the bougie to this gastric tubular pouch, which had a capacity of 60-80 ml. There was no intraoperative requirement of crural repair for any patient.

\section{Statistical analysis}

The data were statistically analyzed using NCSS software (Number Cruncher Statistical System, 2007, Kaysville, Utah, USA). Descriptive statistical methods were applied using the mean, standard deviation, median, minimum, maximum, number, and percentage values. Quantitative variables showing normal distributions were compared using the paired samples test, and the Wilcoxon signed ranks test was used for variables without a normal distri- bution. In the multivariate analysis, factors affecting the DeMeester score were evaluated with linear regression analysis. Statistical significance was evaluated at the levels of $p<0.01$ and $p<0.05$.

\section{Results}

The total of 62 patients comprised 12 (19.4\%) males and 50 (80.6\%) females with a mean age of 40.3 \pm 10.6 years (range: $20-58$ years) (Table I). The mean preoperative BMI of the cases was $47.91 \pm 6.23 \mathrm{~kg} / \mathrm{m}^{2}$. At 3 months postoperatively, the mean BMI was 38 $\pm 7.62 \mathrm{~kg} / \mathrm{m}^{2}$, and the mean weight loss was $27.3 \pm 7.2$ $\mathrm{kg}$. The APM and EM data are shown in Table II.

In the EM examination, all cases had a normal LESL with a mean of $3.39 \pm 0.66 \mathrm{~cm}$ preoperatively, which did not change at 3 months postoperatively, when the mean was $3.34 \pm 0.72 \mathrm{~cm}$. The LESP value was in the normal range preoperatively with a mean of $18.8 \pm 5.1 \mathrm{~mm} \mathrm{Hg}$, which significantly decreased to $16.6 \pm 4.4 \mathrm{~mm} \mathrm{Hg}$ postoperatively, which is still in the normal range $(p=0.004, p<0.01)$. In 2 cases, LESP (7 $\mathrm{mm} \mathrm{Hg}$ ) was consistent with the definition of hypotensive LES ( $<10 \mathrm{~mm} \mathrm{Hg}$ ). This demonstrated that there was a certain amount of regression in the LESP value in almost all the cases. The AP was measured as $84.8 \pm 23 \mathrm{~mm} \mathrm{Hg}$ preoperatively and $80.8 \pm 19.3$ $\mathrm{mm} \mathrm{Hg}$ postoperatively, but the difference was not statistically significant (Table II).

In the comparison of the LESR values, a mean reduction of $0.85 \pm 3.89 \mathrm{mmHg}$ was determined, but the change was not statistically significant ( $p=0.084)$. In contrast to the LESR, a statistically significant increase of $1.90 \pm 2.20 \mathrm{~s}$ was determined in the relaxation time of the LES ( $p=0.001$ ) (Table II). When the change in intragastric pressure was examined, the measurement was $10.69 \pm 3.71$ preoperatively and $10.95 \pm 2.87$ postoperatively with no statistically significant difference $(p=0.609$, $p>0.05$ ) (Table II)

Table I. Distribution of demographic characteristics

\begin{tabular}{|c|c|c|c|}
\hline \multicolumn{2}{|c|}{ Parameter } & Min.-max. (median) & Mean \pm SD \\
\hline \multicolumn{2}{|c|}{ Age [years] } & $20-58(40.5)$ & $40.3 \pm 10.6$ \\
\hline & & $N$ & $\%$ \\
\hline \multirow[t]{2}{*}{ Gender } & Male & 12 & 19.4 \\
\hline & Female & 50 & 80.6 \\
\hline
\end{tabular}


Table II. Comparison of preoperative and postoperative measurements

\begin{tabular}{|c|c|c|c|c|}
\hline \multirow[t]{2}{*}{ Parameter } & & \multicolumn{2}{|c|}{ Measurements } & \multirow[t]{2}{*}{$P$-value } \\
\hline & & Before LSG & 3 months after LSG & \\
\hline \multirow[t]{2}{*}{ BMI } & Mean \pm SD & $47.91 \pm 6.23$ & $38.00 \pm 7.62$ & ${ }^{b} 0.001^{* *}$ \\
\hline & Min.-max. (median) & $37.20-68.40(47.15)$ & $31.60-56.40(37.3)$ & \\
\hline \multirow[t]{2}{*}{ LESL [cm] } & Mean \pm SD & $3.39 \pm 0.66$ & $3.34 \pm 0.72$ & a 0.513 \\
\hline & Min.-max. (median) & $2-5(3)$ & $2-5(3)$ & \\
\hline \multirow[t]{2}{*}{$\operatorname{LESP}[\mathrm{mm} \mathrm{Hg}]$} & Mean \pm SD & $18.8 \pm 5.1$ & $16.6 \pm 4.4$ & ${ }^{b} 0.014^{\star}$ \\
\hline & Min.-max. (median) & 18-30 (19) & $7-29(16)$ & \\
\hline \multirow[t]{2}{*}{$\mathrm{AP}[\mathrm{mm} \mathrm{Hg}]$} & Mean \pm SD & $84.8 \pm 23$ & $80.8 \pm 19.3$ & b0.062 \\
\hline & Min.-max. (median) & $38-129(78)$ & $48-133(78)$ & \\
\hline \multirow[t]{2}{*}{ DeMeester Score: } & Mean \pm SD & $17.26 \pm 15.74$ & $33.84 \pm 26.55$ & ${ }^{b} 0.001^{* *}$ \\
\hline & Min.-max. (median) & $0.74-81.05(12.4)$ & $0.95-113.65(28.76)$ & \\
\hline \multirow[t]{2}{*}{ Total percent time $(\mathrm{pH}<4.0)$} & Mean \pm SD & $5.06 \pm 4.14$ & $9.84 \pm 8.09$ & ${ }^{\mathrm{b}} 0.001^{* *}$ \\
\hline & Min.-max. (median) & $0.10-20.90(4.00)$ & $0.20-31.70(8.60)$ & \\
\hline \multirow[t]{2}{*}{ Total number of reflux episodes $(<50)$} & Mean \pm SD & $54.19 \pm 32.60$ & $65.52 \pm 50.29$ & b0.076 \\
\hline & Min.-max. (median) & $2.10-170.00(47.90)$ & $1-235.90(53.85)$ & \\
\hline \multirow{2}{*}{$\begin{array}{l}\text { Total number of reflux episodes lon- } \\
\text { ger than } 5 \min (<4)\end{array}$} & Mean \pm SD & $2.40 \pm 3.52$ & $5.36 \pm 5.23$ & ${ }^{\mathrm{b}} 0.001^{* *}$ \\
\hline & Min.-max. (median) & $0-17.00(1.00)$ & $0-25.40(4.45)$ & \\
\hline \multirow{2}{*}{$\begin{array}{l}\text { Duration of the longest reflux episode } \\
(<9.2 \mathrm{~min})\end{array}$} & Mean \pm SD & $11.30 \pm 13.65$ & $25.41 \pm 22.96$ & ${ }^{\mathrm{b}} 0.001^{* *}$ \\
\hline & Min.-max. (median) & $1.40-86.80(6.30)$ & $1-89.90(19.45)$ & \\
\hline \multirow[t]{2}{*}{$\operatorname{LESR}[\mathrm{mm} \mathrm{Hg}]$} & Mean \pm SD & $8.12 \pm 3.73$ & $7.27 \pm 3.57$ & a 0.084 \\
\hline & Min.-max. (median) & 0-16 (8.1) & 0-14 (7.2) & \\
\hline \multirow[t]{2}{*}{ Relaxation time of LES [s] } & Mean \pm SD & $4.61 \pm 1.72$ & $6.51 \pm 1.96$ & ${ }^{\mathrm{b}} 0.001^{* *}$ \\
\hline & Min.-max. (median) & $1.10-7.70(3)$ & $1.80-10.70(5.80)$ & \\
\hline \multirow[t]{2}{*}{ Intragastric pressure [mm Hg] } & Mean \pm SD & $10.69 \pm 3.71$ & $10.95 \pm 2.87$ & a 0.609 \\
\hline & Min.-max. (median) & $1-18(10)$ & $3-19(10.50)$ & \\
\hline
\end{tabular}

aPaired samples test, ${ }^{b}$ Wilcoxon signed rank test, ${ }^{* *} p<0.01,{ }^{*} p<0.05$.

In the preoperative APM evaluation, the total DeMeester score was $17.26 \pm 15.74$ (> 14.2), which was to be expected in obese cases. A statistically significant increase was determined in the postoperative measurement of $33.84 \pm 26.55(p=0.001, p<0.01)$. Of the parameters forming the DeMeester score, there was a unit increase in the total number of reflux episodes of $11.32 \pm 49.48$, but not at a statistically significant level $(p=0.076, p>0.05)$ (Table II).

There were statistically significant changes in the total percent time of $\mathrm{pH}<4.0$, the total number of reflux episodes longer than $5 \mathrm{~min}$, and the du- ration of the longest reflux episode measurements $(p=0.001 ; p<0.01)$. A multivariate analysis was done to determine which of these sub-parameters caused an increase in the DeMeester score, and the model was found to be significant. The coefficient explaining the model was found to be at a very good level (91\%) (Table III).

The odds ratio obtained for the total number of reflux episodes was 0.171 (95\% Cl: 0.116-0.226). The odds ratio for the total number of reflux episodes longer than 5 min was 1.866 (95\% Cl: 1.0682.2263), and that for the longest reflux episode was 
Table III. Linear regression analysis of factors affecting the DeMeester score

\begin{tabular}{|lcccc|}
\hline Variable & P-value & Odds & \multicolumn{2}{c|}{$95 \% \mathrm{Cl}$} \\
\cline { 3 - 5 } & & & Lower & Upper \\
\hline Total percent time $(\mathrm{pH}<4.0)$ & 0.176 & 0.399 & -0.184 & 0.981 \\
\hline Total number of reflux episodes $(<50)$ & $0.001^{* *}$ & 0.171 & 0.116 & 0.226 \\
\hline Total number of reflux episodes longer than $5 \mathrm{~min}(<4)$ & $0.001^{* *}$ & 1.866 & 1.068 & 2.663 \\
\hline Duration of the longest reflux episode $(<9.2 \mathrm{~min})$ & $0.001^{* *}$ & 0.371 & 0.258 & 0.489 \\
\hline
\end{tabular}

${ }^{*} p<0.05,{ }^{* *} p<0.01$

0.371 (95\% Cl: 0.258-0.489). According to these results, the parameter creating the greatest difference was determined to be the total number of reflux episodes longer than 5 min (Table III).

\section{Discussion}

Sleeve gastrectomy is a surgical procedure that provides effective weight loss. In the current study, excess BMI loss among the cases at the end of the $3^{\text {rd }}$ month postoperatively was determined as 9.91 \pm 5 .38. Burgerhart et al. reported similar weight loss after 3 months [14]. Weight loss was reported to occur in the early period and decrease after the second year, after which weight was regained [15]. However, as only early-period data were available, it is not possible to make such a conclusion in the current study.

At the end of 3 months postoperatively, the sleeve gastrectomy reduced LESP without any change to LESL and AP or causing an increase in intragastric pressure. Moreover, it caused a longer relaxation time of the LES without changing LESR. The sleeve gastrectomy also increased acid reflux, and an increase was found in the DeMeester score. This difference was mostly caused by the parameter of the total number of reflux episodes longer than $5 \mathrm{~min}$.

In many studies, LSG is accepted as a refluxogenic operation [16-18]. However, no clear correlation has been established between reflux disease and LSG, and it is not possible to explain a pathology with a single variable. Several studies have reported a fall in LESP after LSG $[14,19]$. However, other studies have stated that LESP remains stable without changing, and some have even reported an increase $[20,21]$. Petersen reported an increase in sphincter tonus, which was reflected in the manometric measurement of the surgical technique applied independently of weight loss [20]. A loss of sphincter length and the destruction of the angle of His have been considered the most responsible for the decrease in LESP [22]. However, in the defined technique of LSG, it has been reported that clasp fibers and sling fibers provide protection against contraction of the transection to be made $1-1.5 \mathrm{~cm}$ distal to the angle of His [21]. The contradictions mentioned are found to continue after surgery is applied with an appropriate technique.

A greater relaxation time of the LES and a fall in LESP can be considered as basic factors that explain the pathology. Thus, the lower sphincter remaining open for a longer time prevents clearance of the esophagus and causes greater exposure to acid. Although this argument does not explain the lack of significance in the pressure change in LESR, there are studies with similar findings [23]. No change was seen in the AP, which is consistent with the literature [24]. In the preoperative evaluation, no impairment was seen in the motor function of the esophagus. These types of data can be predicted when there is no surgery-related complication.

Intra-abdominal pressure is known to be high in cases of obesity, and when there is a competent pylorus, a direct increase is caused in the intragastric area. When the intragastric pressure exceeds the LES pressure, pathological reflux occurs. In LSG, the stomach is brought into the shape of a tube with resection of the large curvature. Thus, by removing compliance, there is an increase in pressure in the intragastric area [25].

However, in the current study, there was no increase in intragastric pressure. Some studies have reported a difference in pressure $[26,27]$. Although the reason has not been fully explained, it has been suggested that with a resection made close to the antrum $(<3 \mathrm{~cm})$, the rate of stomach evacuation is increased, and there is stomach drainage without making any change to the intragastric pressure [28]. In the current study, it is thought that there was no 
increase in intragastric pressure because the resection was started $1-2 \mathrm{~cm}$ proximal to the antrum, in accordance with this theory.

There are many examples of a significant increase in the DeMeester score with $24-\mathrm{h} \mathrm{pH}$ monitoring $[21,29,30]$. Nevertheless, there are also studies that have reported no change or even a decrease in the score $[15,24]$. Of the parameters forming the DeMeester score, no significant increase was seen in the total number of reflux episodes, whereas the total number of reflux episodes longer than 5 min was found to have the greatest effect. This was thought to be related to the decrease seen in LESP. It can be said that the duration of contact was increased by exposure to acid rather than the reflux episode. It has been similarly reported that the parameter with the greatest effect is the total number of episodes longer than 5 min [14].

There were some limitations to this study. First, only early results were examined, so no long-term evaluation could be made. The amount of non-acid reflux was not evaluated in the measurements, and yet non-acid reflux forms the largest part of gastroesophageal reflux disease. In addition, symptoms were not assessed with a measurement system such as the Reflux Disease Questionnaire.

\section{Conclusions}

The LSG provides effective weight loss in the early period. In addition, a reduction in LESP leads to prolonged relaxation time of the LES, which causes an increase in acid reflux. This is reflected in the increase in the measured DeMeester score.

\section{Conflict of interest}

The authors declare no conflict of interest.

\section{References}

1. World Health Organization. Obesity: preventing and managing the global epidemic. Report of a WHO consultation on obesity. WHO Technical Support Series. Geneva 1998; 1-276.

2. Angrisani L, Santonicola A, lovino P, et al. Bariatric surgery and endoluminal procedures: IFSO Worldwide Survey 2014. Obes Surg 2017; 27: 2279-89.

3. Dyaczyński M, Scanes CG, Koziec H, et al. Endocrine implications of obesity and bariatric surgery. Endokrynol Pol 2018; 69: 574-97.

4. Sammour T, Hill AG, Singh P, et al. Laparoscopic sleeve gastrectomy as a single stage bariatric procedure. Obes Surg 2010; 20: 271-5.
5. Carlin AM, Zeni TM, English WJ, et al.; Michigan Bariatric Surgery Collaborative. The comparative effectiveness of sleeve gastrectomy, gastric bypass, and adjustable gastric banding procedures for the treatment of morbid obesity. Ann Surg 2013; 257: 791-7.

6. Mion F, Dargent J. Gastro-oesophageal reflux disease and obesity: pathogenesis and response to treatment. Best Pract Res Clin Gastroenterol 2014; 28: 611-22.

7. Dowgiałło-Wnukiewicz N, Frask A, Lech P, Michalik M. Study of the prevalence of gastroesophageal reflux symptoms and the role of each in relation to the GERD Impact Scale, based on a population of patients admitted for laparoscopic surgery compared to a control group. Videosurgery Miniinv 2018; 13 : 199-211.

8. Schlottmann F, Herbella FAM, Patti MG. Bariatric surgery and gastroesophageal reflux. J Laparoendosc Adv Surg Tech A 2018; 28: 953-5.

9. Rebecchi F, Allaix ME, Patti MG, et al. Gastroesophageal reflux disease and morbid obesity: to sleeve or not to sleeve? World J Gastroenterol 2017; 23: 2269-75.

10. Mittal RK, Chiareli C, Liu J, Shaker R. Characteristics of lower esophageal sphincter relaxation induced by pharyngeal stimulation with minute amounts of water. Gastroenterology 1996; 111: 378-84.

11. Mandeville Y, Van Looveren R, Vancoillie PJ, et al. Moderating the enthusiasm of sleeve gastrectomy: up to fifty percent of reflux symptoms after ten years in a consecutive series of one hundred laparoscopic sleeve gastrectomies. Obes Surg 2017; 27: 1797-803.

12. Chuffart E, Sodji M, Dalmay F, et al. Long-term results after sleeve gastrectomy for gastroesophageal reflux disease: a single-center French study. Obes Surg 2017; 27: 2890-7.

13. Peterli R, Wolnerhanssen BK, Vetter D, et al. Laparoscopic sleeve gastrectomy versus Roux-Y-gastric bypass for morbid obesity-3-year outcomes of the prospective randomized Swiss multicenter bypass or sleeve study. Ann Surg 2017; 265: 466-73.

14. Burgerhart JS, Schotborgh CAI, Schoon EJ, et al. Effect of sleeve gastrectomy on gastroesophageal reflux. Obes Surg 2014; 24: 1436-41.

15. Felsenreich DM, Ladinig LM, Beckerhinn P, et al. Update: 10 years of sleeve gastrectomy - the first 103 patients. Obes Surg 2018; 28: 3586-94.

16. Arias E, Martinez PR, Ka Ming Li V, et al. Mid-term follow-up after sleeve gastrectomy as a final approach for morbid obesity. Obes Surg 2009; 19: 544-8.

17. Nocca D, Krawczykowsky D, Bomans B, et al. A prospective multicenter study of 163 sleeve gastrectomies: results at 1 and 2 years. Obes Surg 2008; 18: 560-5.

18. Lakdawala MA, Bhasker A, Mulchandani D, et al. Comparison between the results of laparoscopic sleeve gastrectomy and laparoscopic Roux-en-Y gastric bypass in the Indian population: a retrospective 1 year study. Obes Surg 2010; 20: 1-6.

19. Braghetto I, Lanzarini E, Korn O, et al. Manometric changes of the lower esophageal sphincter after sleeve gastrectomy in obese patients. Obes Surg 2010; 20: 357-62.

20. Petersen WV, Meile T, Kuper MA. Functional importance of laparoscopic sleeve gastrectomy for the lower esophageal sphincter in patients with morbid obesity. Obes Surg 2012; 22: 360-6. 
21. Del Genio G, Tolone S, Limongelli P, et al. Sleeve gastrectomy and development of "de novo" gastroesophageal reflux. Obes Surg 2014; 24: 71-7.

22. Melissas J, Daskalakis M, Koukouraki S, et al. Sleeve gastrectomy - a "food limiting" operation. Obes Surg 2008; 18: 1251-6.

23. Sioka E, Tzovaras G, Tsiopoulos F, et al. Esophageal motility after laparoscopic sleeve gastrectomy. Clin Exp Gastroenterol 2017; 10: 187-94

24. Rebecchi F, Allaix ME, Giaccone C, et al. Gastroesophageal reflux disease and laparoscopic sleeve gastrectomy: a physiopathologic evaluation. Ann Surg 2014; 260: 909-14.

25. Melissas J, Koukouraki S, Askoxylakis J, et al. Sleeve gastrectomy: a restrictive procedure? Obes Surg 2007; 17: 57-62.

26. Coupaye M, Gorbatchef C, Calabrese D, et al. Gastroesophageal reflux after sleeve gastrectomy: a prospective mechanistic study. Obes Surg 2018; 28: 838-45.

27. Mion F, Tolone S, Garros A, et al. High-resolution impedance manometry after sleeve gastrectomy: increased intragastric pressure and reflux are frequent events. Obes Surg 2016; 26 : 2449-56.

28. Garay M, Balagué C, Rodríguez-Otero C, et al. Influence of antrum size on gastric emptying and weight loss outcomes after laparoscopic sleeve gastrectomy (preliminary analysis of a randomized trial). Surg Endosc 2018; 32: 2739-45.

29. Gorodner V, Buxhoeveden R, Clemente G, et al. Does laparoscopic sleeve gastrectomy have any influence on gastroesophageal reflux disease? Preliminary results. Surg Endosc 2015; 29 : 1760-8.

30. Hayat JO, Wan A. The effects of sleeve gastectomy on gastro-esophageal reflux and gastro-esophageal motility. Expert Rev Gastroenterol Hepatol 2014; 8: 445-52.

Received: 11.12.2018, accepted: 3.02.2019. 